\title{
O MULTILETRAMENTO E AS NOVAS TECNOLOGIAS EDUCACIONAIS: ALGUNS APONTAMENTOS EM RELAÇÃO AO ENSINO DA LÍNGUA INGLESA
}

\section{THE MULTILITERACY AND NEW EDUCATIONAL TECNOLOGIES: SOME TOPICS ABOUT TEACHING ENGLISH}

\author{
Lucilea Kalva* \\ Silvio Ruiz Paradiso**:
}

\begin{abstract}
Resumo: Como parte da rotina das pessoas atualmente a tecnologia participa de quase todos os processos sociais, inclusive do (multi) letramento no cotidiano escolar. Desta forma, este estudo tem por objetivo compreender como o multiletramento vem sendo tratado juntamente com as novas tecnologias educacionais e as TIC, especificamente no âmbito do ensino da Língua Inglesa. Essa pesquisa é de caráter bibliográfico, tendo em vista que nela é feito um apanhado de estudos já feitos sobre os temas em questão dialogando com alguns dos autores mais citados da área. Como resultado pode se perceber que é de suma importância o uso das novas tecnologias e do multiletramento no ensino da língua inglesa, pois assim, fazemos com que o educando possa utilizar seu dia-a-dia tecnológico juntamente com os temas teóricos abordados em sala de aula, unindo teoria e prática.
\end{abstract}

Palavras-chave: Multiletramento; TIC; Inglês.

ABSTRACT: As part of people daily life routine nowadays technology is in almost all social processes, even the (multi)literacy in the educational routine. In this way, this paper aims at understanding about the way the multiliteracy has been developed with the new educational technologies and the ICT, pointing out about the teaching of English. This is a biographical study as it has been done throughout reading of other studies with the same subject discussing with some of the most important authors in the area. As a result it is understood that is very important to use new technologies

\footnotetext{
"Especialista - UNICESUMAR. Email: lucileakalva1407@gmail.com.

"* Doutor - Universidade Federal do Recôncavo da Bahia, UFRB, Brasil. ORCID - https://orcid.org/0000-0001-7248-6490. Email: silvinhoparadiso@hotmail.com
} 
when teaching English, so that it will be possible to have a multiliteracy, therefore, students can put in practice theoretical themes bringing together what they have in their routine.

KEYwords: Miltiliteracy; LCTs; English.

\section{INTRODUÇÃo}

Perpassamos por um tempo em que a palavra tecnologia já faz parte de nossa rotina, seja ela: a social, profissional, e principalmente, educacional. Foi-se o tempo em que para podermos obter algo teríamos que ir até o ambiente presencial para realizar uma atividade, por exemplo: se queremos comprar um livro, uma roupa, ou contratarmos algum serviço podemos fazer isso virtualmente. Toda essa tecnologia teve e tem um impacto muito grande em nossas vidas, pois depois dela nada mais foi igual. Porém, precisamos estar cientes de que devemos utilizá-la de maneira produtiva e como uma ferramenta para o nosso bem estar, assim como o de toda a sociedade.

Dessa forma, as novas tecnologias ${ }^{1}$ podem ser trabalhadas na área da educação, de maneira a contribuir para o desenvolvimento de alunos, como também, na melhoria do trabalho do professor. Por essa perspectiva, podemos utilizar a tecnologia como uma ferramenta para a mediação na construção do conhecimento.

Neste trabalho, teve como foco o estudo dos multiletramentos (ROJO, 2009; 2012; 2013), bem como as novas tecnologias (KENSKI, 2007; BRITO \& PURIFICAÇÃO, 2008) dialogando, então, sobre esses tópicos em função do ensino da Língua Inglesa (LIMA, 2009). Para isso, teceremos uma discussão de caráter bibliográfico visando compreender como vêm sendo estudadas essas questões, para que assim possamos entender se há ou não uma preocupação e um esforço em colocar em prática o que está posto no papel.

Dessa forma, para nos dar suporte, alguns autores fizeram parte de nossa discussão. Abordando multiletramentos temos Rojo (2009; 2012; 2013), com seus conceitos e suas implicações em sala de aula e na sociedade. A autora em questão observa que há uma diferença entre o significado de alfabetismo e letramento, sendo o último não apenas a decodificação de letras e sons da fala, mas sim a compreensão do que se lê. Quando almejamos o letramento acionamos nosso conhecimento de mundo para fazer ligações com outros textos e temas.

Sendo assim, para se letrar é preciso interpretar, criticar e dialogar com o texto, percebendo o ponto de vista do autor, bem como a ideologia que está sendo posta neste ou naquele

\footnotetext{
${ }^{1} \mathrm{O}$ termo novas tecnologias designa os recursos tecnológicos que envolvem o uso de computadores e redes telemáticas (internet) que são o conjunto de processos e produtos derivados da informática, suporte de informação e canais de comunicação relacionado com o armazenamento, processamento e transmissão digitalizada de informações. MERCADO, Luiz Paulo Leopoldo. Formação continuada de professores e as novas tecnologias. UFAL, Maceió, 1999.
} 
contexto (ROJO, 2009). Torna-se necessário entendermos, primeiramente, o conceito de letramento para, posteriormente, discutirmos melhor o que vem a ser os multiletramentos.

Tratando então das novas tecnologias, trouxemos alguns autores como: Vani Moreira Kenski (2007) que nos dá um panorama acerca do que é tecnologia e para que a utilizamos. De acordo com a autora, tecnologia é poder (2007, p. 15). E a educação tem um papel fundamental na articulação entre poder, a tecnologia e o conhecimento. Além disso, Kenski (2007) nos adverte que não podemos pensar a tecnologia apenas como máquinas e equipamentos, pois a linguagem também é uma poderosa ferramenta tecnológica.

Ainda sobre novas tecnologias temos Mercado (2002), o qual discorre sobre a formação do professor para essa era tecnológica. Segundo o autor, a função do professor, nesse novo contexto, é de mediador, o qual faz uma ponte entre o educando e como ele utiliza a tecnologia para sua formação, buscando, assim, formar um aluno tecnologicamente autônomo.

Outra importante autora é Behar (2013), a qual aponta as competências necessárias para se obter um letramento digital, muito necessário nessa nossa era da tecnologia e da informação. Para ela, uma pessoa letrada digitalmente tem a habilidade de construir sentido a partir de sons, textos e hiperlinks, hipertextos, etc.; por meio disso, esse indivíduo tem a capacidade de filtrar e analisar criticamente o que utiliza no mundo digital.

Finalmente, temos a questão do ensino e aprendizagem da Língua Inglesa. Elencaremos ainda alguns autores que darão base ao nosso diálogo, entre eles temos Lima (2009), o qual traz um levantamento de vários pesquisadores sobre o ensino aprendizagem de inglês.

\section{OS MULTILETRAMENTOS EM AMBIENTES EDUCACIONAIS}

Como ponto de partida, precisamos conhecer e entender alguns conceitos para desenvolvermos uma análise crítica, pautada em elementos coesivos em relação ao tema de estudo proposto. Assim, faz-se necessário esclarecer o conceito de multiletramento, logo, traremos à baila alguns estudiosos na área para provermos uma discussão sobre o tema, tais como: Street (2003), que dialoga sobre os novos estudos do letramento e Rojane Rojo (2009; 2012; 2013), autora de vários livros e estudos sobre multiletramento.

Primeiramente, letramento de acordo com Street (2003) se trata de uma prática social, entrelaçada ao poder. Consequentemente, temos letramentos dominantes e letramentos marginalizados, e ter consciência desses termos nos faz letrar-se e como resultado acabamos por nos empoderar:

literacy is a social practice, not simply a technical and neutral skill; that is always embedded in social constructed epistemological principles. It is about knowledge: the ways in which people addresses reading and writing are themselves rooted in conceptions of knowledge, identity and being. It is always embedded in social 
practices, such as those of a particular job market or a particular educational context and the effects of learning that particular literacy will be dependent on those particular context ${ }^{2}$. (STREET, 2003, p. 77-78).

Por essa perspectiva, o letramento e o multiletramento são práticas sociais pelas quais todos os indivíduos passam e isso ajuda o educando a fazer uma ligação do que se ensina com o que se aprende, já que ele irá visualizar situações que podem ser colocadas em prática.

Assim para Rojo (2012) o multiletramento se difere do letramento múltiplo, na medida em que este último aponta para a multiplicidade e variedade das práticas letradas, valorizadas ou não, e o multiletramento trata de dois tipos de multiplicidade, sendo uma "a multiplicidade cultural das populações e a multiplicidade semiótica de constituição dos textos por meio dos quais ele se informa e comunica”. (ROJO, 2012, p. 13).

Ou seja, não há apenas uma forma de cultura ou uma única forma dos textos serem apresentados. Essa multiplicidade é o que faz do multiletramento uma ferramenta muito mais poderosa do que apenas alfabetizar um indivíduo.

Com o multiletramento deixamos de ver apenas a necessidade de se decodificar letras e sons, ler e escrever; passamos a valorizar o conhecimento de mundo, a relação com outros textos, o prever, o hipotetizar, o criticar, e o diálogo com o texto, percebendo a ideologia do autor, situando o texto em seu contexto. (ROJO, 2009).

Isso tudo ajuda o indivíduo a construir-se como uma pessoa crítica e analítica, não apenas decodificando sons e letras, mas sim entendendo o que se passa por detrás delas, o que o autor (a) quis dizer e como disse. O texto, seja ele falado, ouvido ou escrito passa a ser uma prática social, assim como tudo o que utilizamos em nosso dia-a-dia, desde o momento em que vamos ao banco até o momento em que assistimos à uma palestra na universidade. Contamos aqui com uma definição do que seria multiletramento:

[...] justamente apontar, já de saída, por meio do prefixo "multi”, para dois tipos de "múltiplos" que as práticas de letramento contemporâneas envolvem: por um lado, a multiplicidade de linguagens, semioses e mídias envolvidas na criação de significação para os textos multimodais contemporâneos e, por outro lado, a pluralidade e a diversidade cultural trazidas pelos autores/leitores contemporâneos a essa criação de significação. (ROJO, 2013, p. 14).

\footnotetext{
${ }^{2}$ Letramento é uma prática social, não simplesmente uma habilidade técnica e neutra; a qual é sempre ligada a princípios construídos epistemologicamente. Trata-se de conhecimento: as maneiras em que as pessoas se remetem à leitura e escrita estão enraizadas em concepções de conhecimento, identidade e ser. Também está ligada à práticas sociais, tais como de um mercado de trabalho em particular ou um contexto educacional em particulares e os efeitos de aprender esse letramento particular irão depender de contextos particulares (Tradução nossa).
} 
Assim, se reforça que a partir de um multiletramento não estamos apenas visualizando letras e sons, mas sim entendendo como o texto, seja ele emitido pela mídia que for, funciona e é construído. Por conseguinte, os educandos têm a oportunidade de entender que podem utilizar o texto, seja ele pertencente à mídia que for, enquanto prática social.

Mas com funcionam os multiletramentos? De acordo com Rojo (2012) algumas características são importantes: eles são colaborativos, transgridem a relação de poder, são híbridos, fronteiriços (de linguagens e modos e mídias e culturas).

Assim, é por meio dos multiletramentos que podemos trabalhar com as novas questões que surgem em nossa educação. Mas não podemos deixar de lado a questão cultural que envolve esse letramento, bem como a identidade que os indivíduos estão formando nesse momento, posto que a tecnologia aliada aos multiletramentos abra o leque de opções e oportunidade para o desenvolvimento educacional do indivíduo.

\section{Multiletramento ENQUANTO PRÁTICA SOCIAL}

É importante ressaltar os multiletramentos enquanto prática social. Essa prática que se dá em nosso dia-a-dia, desde o momento em que lemos um anúncio em uma revista, website, televisão, até nossa ida ao banco, situações que demandam nossa leitura, interpretação e análise.

Portanto, essa prática necessita ser avaliada nos ambientes educacionais para que possamos formar indivíduos críticos e aptos a fazer todas essas análises em relação ao que ocorre em nosso mundo.

Hoje, mudamos nossas atitudes e não apenas fazemos nossas escolhas e leituras por meio de tecnologias milenares como papéis e livros, mas sim por meio de novas tecnologias que a cada dia estão se desenvolvendo mais e mais. De acordo com Lankshear (2007) um indivíduo com algum conhecimento técnico e acesso a um computador ou um aparelho móvel digital tem a oportunidade de criar uma gama de artefatos significativos em um pequeno espaço de tempo, com apenas uma ou duas ferramentas.

Dessa forma, em se tratando de escola não podemos fingir que os alunos em geral não têm essas ferramentas, de acordo com o mesmo autor, vemos que:

They can, for example, create a multimodal text and send it to a person, a group, or an entire comuniity in next to no time and at next to no cost, and receive feedback on this text, almost immediately. The text could be a photoshopped image posted to Flickr.com or to Worth1000.com. It could be an animated birthday card sent to a close friend. It could be a short animated film sequence using toys and objects found at home, complete with an original music soundtrack, embedded within a blog post. It could be a slide presentation of images of some 
event with narrated commentary, or edited video clips from a video game that spoof some aspect of popular culture or that retell some obscure literary work ${ }^{3}$. (LANKSHEAR, 2007, p.51).

Isso tudo já faz parte da rotina de uma grande parte das pessoas, as quais sentem necessidade de utilizá-las para sua formação enquanto cidadãos. Essas tecnologias acima descritas não são mais algo inimaginável, tudo está a um toque e pode ser acessado praticamente de qualquer lugar, a qualquer momento, desde que se possuam as ferramentas necessárias.

\section{O MULTILETRAMENTO NO UNIVERSO DAS TIC ${ }^{4}$}

Como tratar do multiletramento sem levarmos em consideração as TIC (tecnologia da informação e da comunicação)? Elas fazem parte dessa nova maneira de trabalharmos a construção do conhecimento em sala de aula, uma vez que essas tecnologias fazem parte, não apenas do imaginário, mas da vida cotidiana dos educandos. Fingir que nada disso existe e pedir aos alunos que desliguem seus celulares não é a maneira mais adequada para trabalhar com o assunto.

Mas afinal, o que é tecnologia? Ouvimos essa palavra a todo o tempo, porém o que ela implica em nossas vidas? Tecnologia é algo que usamos diariamente, desde como escrevemos hoje, até as máquinas que facilitam nossa rotina (KENSKI, 2007). Contudo, a tecnologia vem de muito antes de pensarmos em existir, desde os homens da era da pedra, os quais apesar de serem mais fracos em relação aos demais animais, conseguiam manter sua sobrevivência e terem sua supremacia por utilizarem determinadas tecnologias: o uso da água, do fogo ou até mesmo de paus ou pedras para matar ou afugentar outros animais (KENSKI, 2007).

Com o passar do tempo os humanos também se utilizaram da tecnologia para algo um pouco mais complexo: a guerra. Os povos que possuíam equipamentos mais potentes puderam se organizar em um exército para subjugarem e acabarem com outros povos. Assim, a tecnologia não é algo simples e de fácil entendimento, tecnologia é poder (KENSKI, 2007).

Muito além de apenas máquinas, computadores, robôs a tecnologia também está inter-relacionada à linguagem, uma das mais expressivas formas de poder que podemos utilizar.

\footnotetext{
${ }^{3}$ Eles podem, por exemplo, criar um texto multimodal e envia-lo para uma pessoa, um grupo, ou uma comunidade inteira quase sem tempo e sem custo, e receber uma resposta desse texto quase imediatamente. $\mathrm{O}$ texto pode ser uma imagem feita no photoshop postada no Flickr.com ou para Worth100o.com. Pode ser um cartão de aniversário animado enviado a um amigo próximo. Poder ser uma sequencia curta de animação usando brinquedo e objetos encontrados em casa, completado com uma trilha sonora original, colocado em blog. Pode ser uma apresentação de slide com imagens de eventos com um comentário narrado, ou vídeo clipes editados de um vídeo game que trazem alguns aspectos da cultura popular ou que recontam alguns trabalhos obscuros de letramento. (Tradução nossa).

${ }^{4}$ A sigla TIC (Tecnologia da Informação e Comunicação) não tem plural, visto que de acordo com as normas da língua portuguesa as siglas são conjuntos formados pelas letras iniciais de várias palavras, usados como uma única palavra pela soletração das letras que o compõem. Logo, tais iniciais também correspondem ao plural de uma ou mais dessas palavras, sem que as iniciais se alterem, pois a marca de pluralização é no final da palavra e não no seu início. (nota dos autores).
} 
Entretanto, o modo como entendemos linguagem passa por (re) significações, ou seja, comunicar-se vai além do falar, emitir sons, agora vemos a linguagem ultrapassar as barreiras tecnológicas, tornando-se, então, ainda mais poderosa.

Nesse contexto entendemos o estudo dos multiletramentos como forma de empoderar-se da linguagem em sentindo mais amplo, indo para além das fronteiras antes limitadoras de conhecimento. Vendo por essa perspectiva, o trabalho com as TIC em sala de aula se faz necessário, pois assim, os alunos têm a oportunidade de se apoderarem de um conhecimento que os trará poder e oportunidade para desenvolver, de maneira mais produtiva, suas atividades.

Mesmo sabendo das vantagens em se trabalhar com as TIC, enfrentamos muitas dificuldades na aceitação dessa nova modalidade de trabalho, tanto por parte dos professores, quanto da direção escolar. Em relação aos professores, muitos ainda têm receio em trabalhar com tecnologia, tendo em vista a falta de conhecimento técnico mais aprofundado, quando chegam a ter conhecimento sobre o tema. Essa situação faz com que muitos ainda prefiram se acomodar, trabalhando apenas com a forma tradicional. Quando abordamos a parte gestora, entendemos que há certa dificuldade em se organizar para implementarem essa nova ferramenta de ensino (ARAGÃO et al., 2014).

Além disso, quando usamos a tecnologia em sala de aula, a perspectiva do que é ser professor acaba sendo repensada, uma vez que neste contexto de mudança o educador não é mais visto como único detentor do conhecimento aquele que apenas o transfere conhecimento para o aluno (FREIRE, 1996), mas sim aquele que é o encaminhador, o mediador para a construção do conhecimento (MERCADO, 2002), fazendo com que o aluno possa desenvolver suas habilidades de forma autônoma e a seu tempo, diferente de um modo tradicional e bancário (FREIRE,1996) em que o conhecimento é apenas depositado no educando, como se o mesmo fosse um quadro em branco.

As TIC ajudam a modificar o ensino tradicional, pois a partir delas o indivíduo tem a oportunidade de se tornar mais crítico e mais autônomo, uma vez que o professor não é mais o único detentor do conhecimento, mas sim um mediador, nesse ambiente o aluno passa de mero observador para interagir, opinar, e discutir sobre conteúdos que até então eram considerados presos a uma única mídia, a qual em muitos casos se resumia ao livro didático. Uma aprendizagem por meio da web, por exemplo, é espontânea e natural:

A aprendizagem através de seus recursos é natural e espontânea, pois Podemos selecionar os materiais e escolher nossos caminhos de acordo Com nossos interesses e motivação. A aprendizagem se dá através de descobertas individuais, de solução de problemas, de tentativas diversas, do fazer e refazer, de acordo com o ritmo de cada um. Mas a Web não é apenas um local para se resolver problemas. É um local para apresentar novas ideias, experimentar, criar. (PAIVA, 2001, p. 97). 
Mesmo o ensino de línguas, o qual sempre foi permeado por algumas tecnologias tais como o rádio, TV, fitas cassetes, entre outras, com o objetivo de se trabalhar habilidades de listening ${ }^{5}$ por exemplo, vem se deparando com novas ferramentas para concretizar os mesmo objetivos.

As redes sociais amplamente usadas por indivíduos das mais diferentes identidades e que trazem uma diversidade de mídias em uma mesma tela, são uma das maneiras de se trabalhar as habilidades da língua inglesa diferentemente daquelas utilizadas anteriormente.

De acordo com Provenzo (2011), essas redes sociais não são apenas utilizadas para fins pessoais de divertimento, mas também para se difundir assuntos relacionados ao trabalho e ao estudo, muitas universidades, por exemplo, criam páginas para se comunicarem com seus alunos e isso acaba criando um espaço de multiletramento, o qual recebe os mais diversos tipos de pessoas, ampliando cada vez mais sua repercussão, tornando acessível para milhões de indivíduos.

Todavia, para que as redes sociais funcionem como um espaço para o multiletramento é necessário que os alunos obtenham uma formação adequada para que possam utilizar melhor e mais corretamente esse universo da web, navegando nele de forma critica. Tendo isso em mente, entendemos que o multiletramento promove um discernimento maior com relação ao uso desses novos ambientes, fazendo com que os alunos consigam utilizá-lo de forma consciente.

Por isso, é necessário que se tenha uma visão crítica, analisando criteriosamente o que é postado nesses ambientes. Para isso, o professor tem papel fundamental, pois sua função é "a criação de estratégias para que esses alunos alcancem não apenas um bom uso das ferramentas, mas apliquem-nas de forma construtiva e diferenciada” (BEHAR, 2013, p. 214). Assim, educador + multiletramento + TIC ajudam na construção de um conhecimento melhor estruturado e pronto para ser utilizado nesta nova era da tecnologia e da informação, a qual só tem a crescer.

\section{ENSINO DA LÍNGUA INGLESA À LUZ DO MULTILETRAMENTO EM CONJUNTO COM AS TIC: ALGUNS ESTUDOS.}

O ensino de Língua Inglesa é desenvolvido desde escolas públicas/privadas até cursos particulares de inglês. Sabendo que essa língua é a mais utilizada no mundo globalizado e consequentemente no mundo das mídias ela não pode ser esquecida quando abordamos o ensino baseado nos multiletramentos.

Como dito anteriormente, a linguagem é uma das formas de poder que mais se destacam em nossa sociedade e vale lembrar que a língua inglesa não é apenas mais uma língua

${ }^{5}$ Listening se trata da parte de áudio das aulas de língua estrangeira. Nas aulas de língua inglesa temos quatro habilidades que devem ser trabalhadas: Speaking (fala); Writing (escrtia); Reading (leitura) e Listening (audição). (nota dos autores) 
estrangeira, mas sim uma língua internacional (RAJAGOPALAN, 2004), pois ela não "pertence" a apenas um único país, mas sim a vários indivíduos que dela se utilizam para se comunicarem.

É justamente sobre essa utilização que, em uma entrevista dada a Maria Nilva Pereira (2009), o estudioso Rajagopalan comenta que enquanto professores de inglês devemos preparar nossos alunos para serem participantes desse novo mundo, e assim, os alunos têm que aprender a lidar com todas as maneiras de se falar inglês, não valorizando apenas uma ou outra forma. E essa língua internacional faz parte de todo o universo das TIC, uma vez que é ela que faz a ponte entre quem escreve e quem lê, escuta e discute. Logo, o ensino/aprendizado dessa língua é muito importante.

Porém, não devemos esquecer que ela deve ser vista nesse emaranhado de informações que é o mundo tecnológico. Não temos apenas livros didáticos e livros textos para estudarmos e ensinarmos a língua inglesa. Hoje podemos encontrar um suporte muito grande de material: blogs, web sites, redes sociais, canais de vídeos, entre outros que proporcionam um canal maior de utilização e difusão dessa língua.

Sendo assim "o ensino de línguas estrangeiras, atualmente, lida com metas ambiciosas como estas: capacitar o aprendiz a ler e compreender criticamente os textos (de diferentes tipos e gêneros [...])." (LIMA, 2009, p. 48).

Dessa forma, busca-se trabalhar com diversos veículos de informação e textos, e também com instrumentos tecnológicos que colaborem para o multiletramento em sala de aula, não se lendo apenas por ler, mas entendendo criticamente o que aquele texto, naquele contexto quer dizer.

Logo, vários estudos têm sido feitos para se analisar e discutir sobre a importância do uso de novas tecnologias para o ensino da língua inglesa, de forma a não apenas alfabetizar, mas multiletrar o educando, o qual não apenas lê as letras, mas também sons, imagens, hipertextos, vídeos, etc. (ROJO, 2012). Assim, vejamos alguns exemplos desses estudos.

\section{ENSINO DA LÍNGUA INGLESA E MEIOS TECNOLÓGICOS}

Iniciando, trataremos da questão dos blogs, uma forma de hipertexto que conecta um texto a outro texto, hierarquiza e seleciona áreas de sentido, tecendo ligações a outros documentos (LEVY, 1996). Desta forma, a partir de hipertextos podemos fazer uma leitura multiletrada dos documentos.

Antes de tratarmos sobre as pesquisas, é importante que entendamos do que se trata um blog. O blog é uma das ferramentas mais utilizadas para a comunicação na internet, o indivíduo que coordena um esse espaço é chamado de blogueiro, e faz suas atualizações diariamente, semanalmente ou mensalmente e as pessoas podem acompanhar seus posts. (INFOESCOLA, 2014). 
Por esta perspectiva, o blog se torna uma ferramenta pela qual os grupos podem realizar atividades, postar dúvidas e discutir sobre suas opiniões, trazendo o que se faz em um mundo real, para um mundo digital. Portanto, já há várias pesquisas sobre o uso desse tipo de ferramenta no ensino de língua estrangeira, levando em consideração que a partir do uso de blogs pode-se trazer a língua dentro de seu contexto real e não apenas uma imitação desse mundo.

No estudo de Oliveria e Cardoso (2009) intitulado Novas perspectivas no ensino de Língua Inglesa: Blogues e Podcasts ${ }^{6}$, o autor faz uma pesquisa sobre como os blogs e podcasts podem colaborar com o ensino de língua inglesa em uma turma de oitava série, a qual por meio da construção de um blog cria seus próprios podcasts em grupos, fazendo, por conseguinte, uso efetivo da linguagem por meio dos multiletramentos, levando o mundo real para a escola.

De acordo com o resultado da pesquisa, a qual foi desenvolvida em três módulos, os alunos tiveram uma ótima aceitação e apreciação do trabalho. Como um dos resultados, ficou claro que os alunos puderam desenvolver suas atividades de acordo com o ritmo de cada um. Já que se trata de uma sala heterogênea, com indivíduos uns com mais outros menos facilidade no uso da língua, ficou inclusiva a forma de trabalho.

Outro ponto importante foi a porcentagem de alunos que se disseram estar mais interessados nas aulas após o uso dos blogs como forma de ensino: 95\% aprovou o método utilizado, entendendo assim, que essa maneira de trabalho consegue agrupar mesmo alunos mais distantes. Além disso, pudemos notar que o trabalho permitiu, que os alunos utilizassem a língua de forma autêntica, numa linguagem do dia-a-dia, e a partir dos podcasts tiveram a oportunidade de melhorar sua pronúncia, leitura e expressão oral em Língua inglesa.

Outra pesquisa feita em relação aos blogs foi com as autoras Lorenzi (2012) e Pádua, as quais trazem o título: Blog nos anos iniciais do Fundamental I: a reconstrução de sentido de um clássico infantil. Aqui, diferentemente do primeiro texto citado, elas estudam o uso dessa ferramenta para a produção e reconstrução de um texto infantil.

Percebe-se, a partir desse estudo, que mesmo se tratando de crianças, os alunos já tinham uma noção do que se tratava um blog, e se mostravam ambientadas e dispostas a trabalharem com o mesmo. Indo ao encontro com o que já discutimos, a partir do uso dessa tecnologia, os alunos se tornaram mais cooperativos e independentes, construindo seu próprio conhecimento com a mediação de professores.

E não apenas os blogs ajudam na construção de conhecimento para o ensino de língua Inglesa, o uso de materiais tecnológicos, como os laptops e o e-board7 também colaboram na utilização da língua ensinada de maneira mais real e com aspectos da personalidade e ambientação dos educandos.

\footnotetext{
${ }^{6}$ Podcast significa um produto transmitido via podcasting, ou seja, por áudio ou vídeo. Porém, também podemos encontrar os termos audiocast e videocast ( SPYER,2009)

${ }^{7}$ E-board se trata de um quadro interativo, no qual há a possibilidade de se mover com as próprias mãos, trabalhando diretamente com a internet também. (nota dos autores)
} 
Ainda apresentando algumas pesquisas sobre o tema, em artigo escrito pela professora Fátima Maria Bagatini (2009) em uma escola estadual, os alunos tinham contato com a língua inglesa escrita por meio de troca de e-mails com a professora e com os seus colegas, bem como o uso de um blog para exporem seus textos.

Como resultado da pesquisa, verificamos que a cooperação entre os colegas era muito grande, não apenas na hora de sanar dúvidas, mas também para trabalharem no blog. Pode-se perceber que houve um estimulo à pesquisa, à produção e ao desenvolvimento da criatividade dos alunos, utilizando a língua inglesa de forma prática, com um objetivo de comunicação (BAGATINI, 2009).

Dessa forma, fica evidente que o uso desses instrumentos tecnológicos colaboram para a construção de conhecimento referente à aprendizagem do inglês como segunda língua, pois não temos algo mecânico e "inventado", mas sim, algo natural e produtivo.

E como citado anteriormente, o uso de e-board também se trata de uma ferramenta tecnológica para o ensino de uma língua estrangeira. $\mathrm{O} e$-board é um instrumento que vem sendo implementado em algumas escolas, a maioria ainda particulares, é verdade, mas que pode ser utilizado de maneira a incentivar o uso da língua, principalmente por sua interatividade com todo o conteúdo que há na rede.

Entretanto, esse instrumento deve ser utilizado em forma de cooperação e da autonomia, diferentemente do que se observou em uma pesquisa feita por Oliveira (2009), a qual verificou que apesar de os professores citarem a importância do e-board e toda a sua utilização em sala de aula, no momento das observações constatou-se que havia apenas uma troca do livro didático pelo uso do quadro, em que os alunos continuavam fazendo suas atividades em seus livros, sem interagirem com o conteúdo, e o professor continuava ser o detentor do conhecimento, pois ele tinha o poder de gerenciar o quadro.

Isso mostra que apesar de muitas pesquisas apontarem para a importância do uso de elementos tecnológicos em sala de aula, ainda há certa dificuldade com seu uso, tendo em vista que ainda se tem apenas uma troca do material didático tradicional pelo material eletrônico.

\section{ConsideraçõEs finaIs}

Tecnologia. Essa palavra faz parte de, praticamente, todas as atividades que realizamos em nossas vidas. A cada dia nos acostumamos mais com palavras que fazem parte desse universo: internet, podcasts, blogs, e-mails, entre tantas outras. Isso tudo está nas salas de aula, onde temos a oportunidade de trabalharmos com ferramentas as quais colaboram para um desenvolvimento mais efetivo dos educandos, fazendo com que possam utilizar o que aprendem na escola em suas vidas, enquanto práticas sociais. 
Então, torna-se importante entender que não basta apenas alfabetizarmos os alunos, mas também trabalharmos com eles de forma a multiletra-los, para que possam utilizar de maneira produtiva essas novas ferramentas disponibilizadas.

Tornar os indivíduos pessoas críticas, as quais podem analisar, interpretar e dialogar com os textos, sejam eles da maneira que forem: escritos em livros, revistas, em blogs e nas redes sociais que os indivíduos fazem parte.

O ensino da língua inglesa faz parte dessa nova realidade em que vivemos. Pensar em uma segunda língua como o inglês já é parte da rotina de muitos indivíduos e este ensino não é mais algo pautado apenas em gramática e vocabulário. Os indivíduos estão se utilizando da língua para todas as atividades que realizam, desde a leitura de um texto on-line, pesquisas na internet, músicas que escutam, filmes que assistem, emprego que procuram, entre tantas outras.

Assim, utilizar as novas tecnologias para o ensino da língua se torna primordial, uma vez que os educandos podem aprender com aquilo que já usam, dando mais sentido a sua aprendizagem.

Porém, pudemos perceber que os educadores precisam estar mais bem preparados para o uso das TIC para o multiletramento, pois muitas vezes o professor ainda sente dificuldade no tratamento com as questões tecnológicas.

\section{REFERÊNCIAS}

ARAGÃO, R.; BEATO, Z.; SANTOS, T. F. As Tic's e o Ensino de Línguas. In: Anais UESC. Disponível em: www.uesc.br/eventos/sesexle/anais/10.pdf. Acesso em 15 de março de 2014.

BAGATINI, F. M. A língua inglesa além dos muros da escola: invadindo o muro digital. In: Revista E-curriculum, Junho, 2009. Disponível em www.redalyc.org/artigo.oa?id=76613022017. Acesso em 15 de Março de 2018.

BEHAR, P. A. (org). Competências em educação a distância. Porto Alegre: Penso, 2013.

BRITO, G. da S; PURIFICAÇÃO, I. da. Educação e novas tecnologias: um repensar. Curitiba: Ibpex, 2008.

FREIRE, P. Pedagogia da Autonomia: Saberes necessários à prática educativa. São Paulo: Paz e Terra, 1996.

INFOESCOLA. O que é um Blog? Disponível em http://www.infoescola.com/informatica/oque-sao-blogs/ Acesso em 10 de abril de 2018.

KENSKI, V. M. Educação e tecnologias: o novo ritmo da informação. Campinas/SP: Papirus, 2007.

LANKSHEAR, C.; KNOBEL, M. 'New' Literacies: Technologies and Values. Third Edition, Open University Press,2011. 
LEVY, P. O que é o Virtual? Tradução de Paulo Neves. São Paulo: Editora 34Lda. 1996.

LIMA, D. C. de. Ensino aprendizagem de língua inglesa: conversas com especialista. São Paulo, Parábola editorial, 2009.

LORENZI, G. C. C.; PÁDUA, T.-R. W. de. Blog nos anos iniciais do fundamental I: a reconstrução de sentido de um clássico infantil. In: ROJO, R. Multiletramentos na escola. São Paulo, Parábola editorial, 2012.

MERCADO, L. P. L. (org). Novas tecnologias na educação: reflexões sobre a prática. Maceió: Edufal, 2002.

MERCADO, L. P. L. Formação continuada de professores e as novas tecnologias. UFAL, Maceió, 1999.

OLIVEIRA, A. P. de. O uso da Lousa Eletrônica no ensino de Inglês como segunda língua: em que estágio estamos? NET, Rio de Janeiro, dez. 2009. Revista Linguística. Disponível em http:// www.letras.ufrj.br/poslinguistica/revistalinguistica. Acesso em 10 de abril de 2014.

OLIVEIRA, A. S. \& CARDOSO, E. L. Novas Perspectivas no Ensino da Língua Inglesa: Blogues e Podcasts. In: Educação, Formação \& Tecnologias, vol.2; p.p. 87-101, maio de 2009. Disponível em: http://eft.educom.pt. Acesso em 31 março 2014. (2009).

PAIVA, V. L. M. de O. e. WWW e o ensino de Inglês. Revista Brasileira de Linguística Aplicada, 2001. Disponível em: www.veramenezes.com. Acesso em 15 de abril de 2018.

PEREIRA, M. N. O inglês como língua internacional na prática docente. In: LIMA, D. C. de. Ensino e Aprendizagem de língua inglesa: conversas com especialistas. São Paulo: Parábola, 2009.

PROVENZO, E. F. Multiliteracies:Beyond text and written word. Information Age Pub, 2011. RAJAGOPALAN, K. The concept of "world English"and its implications for ELT. ELT Journal, V. 58, n. 2, 2004. pp. 111-117.

ROJO, R (org). Multiletramentos na escola. São Paulo: Parábola, 2012.

ROJO, R. Escola Conectada: os multiletramentos e as TICs. São Paulo: Parábola, 2013.

ROJO, R. Letramentos Múltiplos, escola, inclusão social. São Paulo: Parábola, 2009.

STREET, B. What's new in literacy studies? Critical approaches to literacy in theory and practice. In: Current issues in comparative Education. Columbia University, 2003.

SPYER, J. (org). Para entender a internet. Noções, práticas e desafios da comunicação em rede. Não zero. 2009.

Recebido para publicação em 25 out. 2017. Aceito para publicação em 14 nov. 2018. 